\title{
Effector Phenotype and Immunologic Specificity of T Cell-Mediated Adoptive Therapy for a Murine Tumor that Lacks Intrinsic Immunogenicity ${ }^{1}$
}

\author{
Keisuke Sakal, ${ }^{2}$ Alfred E. Chang, and Suyu Shu ${ }^{3}$ \\ Department of Surgery, University of Michigan, Ann Arbor, Michigan 48109
}

Received February 27, 1990; accepted April 2, 1990

\begin{abstract}
The MCA 102 sarcoma has been defined by a variety of immunologic studies as a tumor lacking intrinsic immunogenicity. Nevertheless, we have recently demonstrated the feasibility of generating therapeutically effective lymphocytes for adoptive immunotherapy of this tumor. Procedures to achieve this required in vivo priming of syngeneic mice to elicit preeffector cells followed by in vitro sensitization (IVS) with tumor cells in the presence of IL-2. By selective depletion of $\mathrm{T}$ cell subsets in vivo, we identified the involvement of both $\mathrm{CD}^{+}\left(\mathrm{L}^{3} 4^{+}\right)$and $\mathrm{CD8}^{+}\left(\mathrm{Lyt}^{-2}{ }^{+}\right) \mathrm{T}$ cells in mediating tumor regression. The $\mathrm{CD}^{+}$cells exerted their helper function via the secretion of IL-2 because antitumor effects abrogated by depletion of $\mathrm{CD}^{+}$cells could be reconstituted by exogenous IL-2. In order to elicit preeffector cells with reactivity against the MCA 102 tumor, we found that in vivo sensitization could be accomplished with either the MCA 102 or MCA 106 tumor but not with the MCA 101 or MCA 105 tumor. Analysis of specificity of tumor stimulation during IVS of MCA 102 tumor-primed preeffector cells demonstrated cross-reactivity between not only the MCA 102 and MCA 106 tumors but also the MCA 105 tumor whereas the MCA 101 tumor was ineffective. In adoptive immunotherapy, transfer of IVS cells generated from MCA 102 tumor-primed and stimulated lymph node cells was able to mediate reductions of pulmonary metastases established from the MCA 102, MCA 105, and MCA 106 tumors but not from the MCA 101 tumor. We conclude that regression of the MCA 102 tumor is probably mediated through T cell recognition of a set of common tumorassociated Ag shared by several other syngeneic tumors. Immunologically, the tumor-associated $\mathrm{Ag}$ are characteristically different from classical tumor-specific transplantation $\mathrm{Ag}$ (TSTA) because immunity to TSTA on the MCA 105 or MCA 106 tumor does not cross-react with the MCA 102 tumor. Thus, this study demonstrates that Ag other than TSTA on chemically induced tumors can serve as target molecules for $\mathrm{T}$ cell-mediated adoptive immunotherapy. (C) 1990 Academic Press, Inc.
\end{abstract}

\section{INTRODUCTION}

Adoptive immunotherapy of cancer is defined as the transfer, to the tumor-bearing host, of lymphoid cells with antitumor reactivity that can mediate the regression of

\footnotetext{
${ }^{1}$ This study was supported in part by United States Public Health Service Grant CA-49231 from the National Cancer Institute, by Grant IM-494 from the American Cancer Society, and by Institutional Research Grant IN-40-30 to the University of Michigan from the American Cancer Society.

${ }^{2}$ Current address: First Department of Surgery, University of Tokyo, Japan.

${ }^{3}$ To whom correspondence and reprint requests should be addressed at Oncology Laboratory, Department of Surgery, 1520 MSRB I, Box 0666, University of Michigan, Ann Arbor, MI 48109-0666.
} 
tumor. This approach is conceptually developed based on observations made in a variety of experimental models over the past three decades (1-9). Among various effector cells, the most potent has been identified to belong to $\mathrm{T}$ lymphocytes specifically sensitized to the tumor. In animal studies, immune lymphocytes can readily be raised by immunization of syngeneic animals. Although theoretically attractive, it is difficult to extrapolate these laboratory observations to the treatment of human cancer largely because of the lack of reliable techniques to identify and generate suitable autologous $T$ cells with antitumor reactivity.

A prerequisite for the clinical application of adoptive $T$ cell immunotherapy is the establishment of in vitro methods to propagate tumor-immune autologous lymphocytes from cancer patients. Using defined murine tumor models, MCA 105 and MCA 106 sarcomas, we have recently identified a culture system where tumor-immune $T$ cells could be further sensitized and expanded in vitro (10). The in vitro sensitization (IVS) ${ }^{4}$ method, consisting of stimulation of lymphocytes with tumor cells in the presence of IL-2, was also found to induce differentiation of immune effector cells (1112). Employing the IVS procedure, we have successfully demonstrated the therapeutic efficacy of $T$ lymphocytes derived from mice bearing progressively growing tumors (13-14). Since freshly isolated lymphoid cells from tumor-bearing animals expressed little or no antitumor effects when tested in adoptive immunotherapy experiments, they were functionally referred to as "preeffector" cells. It appears that progressive tumor triggered the preeffector cell response and under the conditions of IVS, these cells further differentiated to acquire full antitumor effector functions. Of particular significance is that lymph nodes $(\mathrm{LN})$ draining the growing tumor contained most of the preeffector cells and after IVS, could mediate the regression of advanced metastases established in the liver and lung (15).

While these observations have clear clinical implications, the animal tumor models, MCA 105 and MCA 106 sarcomas, employed were demonstrably immunogenic to their syngeneic hosts, i.e., capable of eliciting specific antitumor immunity by experimental immunization procedures $(9,16)$. In recent years, there has been a long and lively debate regarding the propriety of using immunogenic animal tumors as models for human immunotherapy since human tumors are naturally arisen and may not be sufficiently immunogenic (17-19). Successful T cell adoptive immunotherapy has only been demonstrated with the use of immunogenic animal tumors. Sensitization of $T$ lymphocytes against tumors of less immunogenicity may require additional immunologic manipulations which have not received significant experimentation.

To explore the therapeutic potential of $\mathrm{T}$ cell-mediated adoptive therapy against poorly immunogenic tumors, we have selected and used a syngeneic murine tumor, MCA 102, as a model system because of the apparent lack of demonstrable tumorspecific transplantation Ag (TSTA) $(16,20)$. Other biological characteristics exhibited by the MCA 102 sarcoma also suggested the nonimmunogenic nature of this tumor. In contrast to immunogenic tumors, the MCA 102 sarcoma has been shown to be refractory to the in vivo antitumor effects of $\operatorname{TNF}(21,22)$ and treatment of advanced MCA 102 metastases with high-dose IL-2 was not therapeutically effective (16). Fi-

\footnotetext{
${ }^{4}$ Abbreviations used: B6, C57BL/6J; LN, lymph node; IVS, in vitro sensitization (sensitized); CM, complete medium; FMF, flow microfluorimetry (metric); TSTA, tumor-specific transplantation Ag; RIg, rat Ig; LAK, lymphokine-activated killer.
} 
nally, efforts to generate effector cells for therapy from MCA 102 tumor-infiltrating lymphocytes have not been successful $(23,24)$. Therefore, the use of MCA 102 sarcoma might provide a unique opportunity to delineate tumor-host interactions that may not be revealed by using immunogenic animal tumors.

Despite the apparent lack of immunogenicity, our recent results employing the MCA 102 sarcoma have demonstrated the feasibility of generating therapeutically potent lymphocytes (20). The procedures to achieve this involved in vivo priming of syngeneic mice with a mixture of tumor cells and a bacterial adjuvant, Corynebacterium parvum (C. parvum), followed by IVS of draining LN cells. In the present study, we have further analyzed the characteristics of the effector cells and of tumor regression mediated by these effector cells. Experiments were carried out to determine the immunologic specificity of in vivo tumor priming, tumor stimulation during IVS, as well as tumor regression following adoptive immunotherapy to provide clues for delineating the nature of the target $\mathrm{Ag}$ present on MCA 102 tumor cells.

\section{MATERIALS AND METHODS}

Mice. Female C57BL/6J (B6) were purchased from The Jackson Laboratory (Bar Harbor, ME). They were maintained in specific pathogen-free environments and were used in experiments when 10 weeks old or older.

Tumors. The MCA 102 sarcoma was induced by im injection of $0.1 \mathrm{ml}$ of $1 \% 3-$ methylcholanthrene in sesame oil. The MCA 102 tumor does not possess demonstrable immunogenicity because all attempts to immunize syngeneic animals have failed $(16,20)$. Two weakly immunogenic tumors, MCA 105 and MCA 106 and another syngeneic tumor, MCA 101, induced identically to that of MCA 102, were used for specificity controls $(9,16)$. All tumors were maintained in vivo in syngeneic mice by serial sc or im transplantation of cryopreserved tumor samples. Tumors used for the current study were in the 5 th to 7 th transplantation passage.

Single-cell suspensions were prepared from solid tumors by digestion with constant stirring in $40 \mathrm{ml}$ of HBSS (GIBCO, Grand Island, NY) containing DNase $(0.1 \mathrm{mg} /$ $\mathrm{ml})$, collagenase $(1 \mathrm{mg} / \mathrm{ml})$, and hyaluronidase $(2.5 \mathrm{U} / \mathrm{ml}$; Sigma Chemical Co., St. Louis, MO) for $3 \mathrm{hr}$ at room temperature.

$L N$ cell preparations. Inguinal LN draining an intradermal inoculation of $3 \times 10^{6}$ tumor cells admixed with $25 \mu \mathrm{g} \mathrm{C.} \mathrm{parvum} \mathrm{for} 7$ days were removed aseptically. Single-cell suspensions were prepared by teasing with $20 \mathrm{G}$ needles followed by pressing with the blunt end of a 10-ml plastic syringe plunger in HBSS. Routinely, each LN yielded 2 to $3 \times 10^{7}$ nucleated cells. Cell preparations were filtered through a layer of No. 100 nylon mesh (Nytex, TETKO, Inc., Elmsford, NY) and centrifuged, and then $\mathrm{E}$ were lysed if necessary by brief treatment with ammonium chloride-potassium lysing buffer (8.29 $\mathrm{g} \mathrm{NH}_{4} \mathrm{Cl}, 1.0 \mathrm{~g} \mathrm{KHCO}_{3}$ and $0.0372 \mathrm{~g}$ EDTA/1, $\mathrm{pH} 7.4$ ).

$I L-2$. Human rIL-2 was kindly supplied by the Cetus Corp., (Emeryville, CA). Purified material had a specific activity of 6 to $8 \times 10^{6} \mathrm{U} / \mathrm{mg}$. The endotoxin level in the preparation was less than $0.1 \mathrm{ng} / 10^{6} \mathrm{U}$ IL-2 activity, as measured in a standard limulus assay.

IVS of LN cells. The procedure for IVS was carried out in 24-well, flat-bottomed tissue culture plates as described previously (20). Briefly, $4 \times 10^{5} \mathrm{LN}$ cells were cultured with $2 \times 10^{5}, 4000 \mathrm{R}$ irradiated MCA 102 tumor cells in the presence of $10 \mathrm{U} /$ $\mathrm{ml}$ of IL-2 in $2 \mathrm{ml}$ of complete medium (CM). CM was composed of RPMI 1640 
with $10 \%$ heat-inactivated fetal bovine serum, $0.1 \mathrm{~m} M$ nonessential amino acids, 1 $\mu M$ sodium pyruvate, $2 \mathrm{~m} M$ L-glutamine, $100 \mathrm{U} / \mathrm{ml}$ penicillin, $100 \mu \mathrm{g} / \mathrm{ml}$ streptomycin, $50 \mu \mathrm{g} / \mathrm{ml}$ gentamicin, $0.5 \mu \mathrm{g} / \mathrm{ml}$ fungizone (all purchased from GIBCO) and 5 $\times 10^{-5} M$ 2-ME (Sigma). The culture plates were incubated at $37.5^{\circ} \mathrm{C}$ in a moist atmosphere with $5 \% \mathrm{CO}_{2}$. Each well was fed with approximately $1.0 \mathrm{ml}$ of $\mathrm{CM}$ containing $10 \mathrm{U} / \mathrm{ml}$ IL-2 on Day 5 or 6 . Routinely, cells were harvested on Day 8 or 9 when they grew to a high density. In some experiments, these cells were layered on a 28 and $46 \%$ discontinuous Percoll gradient and were centrifuged at $400 \mathrm{~g}$ for $20 \mathrm{~min}$ at room temperature to remove dead cells and debris. Cells resided in the interface between the two layers of Percoll were collected, washed twice and resuspended in HBSS for adoptive immunotherapy.

Adoptive immunotherapy. B6 mice were injected with 2 to $4 \times 10^{5}$ MCA 102 tumor cells in $1.0 \mathrm{ml}$ of HBSS through the tail vein to initiate pulmonary metastases. Three to 4 days later, IVS cells suspended in $1.0 \mathrm{ml}$ of HBSS were given iv to each mouse. In most experiments, mice receiving cells were also injected ip with IL-2 ( $7500 \mathrm{U}$ in $0.5 \mathrm{ml}$ of HBSS) twice a day for 4 days. In all experiments, at least five mice were included in each treatment group unless otherwise stated. At Days 12 to 15 after tumor induction, the mice were ear-tagged, randomized, and sacrificed for enumeration of metastatic pulmonary nodules by a previously described method (25). Briefly, a $15 \%$ india ink solution was instilled to the lung through the trachea followed by bleaching with Fekete's solution. Metastases of the MCA sarcomas formed discrete white nodules on the blackened surface of the lungs and were readily visible. Nodules were counted in a blinded fashion without knowledge of the treatment of that mouse. Lungs with metastases too numerous to count were assigned an arbitrary value of 250 , because we were unable to reliably enumerate more than 250 tumor nodules from one set of lungs.

In vivo depletion of $T$ lymphocyte subsets by $m A b$. Two hybridomas producing rat $\mathrm{IgG}_{2 \mathrm{~b}}$ mAb against the CD4 (L3T4, GK 1.5) and CD8 (Lyt-2, 2.43) T cell antigens were obtained from the American Type Culture Collection (Rockville, MD). The $\mathrm{mAb}$ were produced as ascites following inoculation of hybridoma cells into sublethally irradiated ( $500 \mathrm{R}$ ) DBA/2 mice. For in vivo depletion of T cell subsets, B6 mice were injected iv with $0.2 \mathrm{ml}$ of monoclonal ascites fluid diluted to $1.0 \mathrm{ml}$ with HBSS. In adoptive immunotherapy experiments, the mAb were given within $1 \mathrm{hr}$ of cell transfer. This procedure for in vivo depletion of $\mathrm{T}$ lymphocyte subsets has previously been shown to be effective $(11-13,16)$.

Flow microfluorimetry (FMF) analysis. Analysis of cell surface phenotypes was carried out primarily by indirect immunofluorescence. Single-cell suspensions $\left(10^{6}\right)$ were incubated with $25 \mu \mathrm{l}$ of appropriately diluted $\mathrm{mAb}$ in phenol red-free HBSS containing $2 \%$ fetal bovine serum and $0.1 \% \mathrm{NaN}_{3}$ for $45 \mathrm{~min}$ at $4{ }^{\circ} \mathrm{C}$. Bound $\mathrm{Ab}$ were detected by incubation with $20 \mu \mathrm{l}$ of FITC-labeled mouse mAb to rat $\kappa$-light chains (MAR 18.5; Becton-Dickinson, Mountain View, CA) for $45 \mathrm{~min}$ at $4^{\circ} \mathrm{C}$. In some experiments, two-color staining was performed with FITC-labeled anti-L3T4 (a gift from Dr. James C. Yang, National Cancer Institute, Bethesda, MD) and biotin-labeled anti-Lyt-2.2 (Becton-Dickinson) counterstained with $B$-phycoerythrin-conjugated egg white avidin (PE; a gift from Dr. Bernard Fox, National Cancer Institute). All stained preparations were fixed in $1 \%$ paraformaldehyde solution and analyzed by a FACScan flow microfluorometer (Becton-Dickinson) for a minimum of 10,000 cells/sample. 
TABLE 1

Effect of Administration of Exogenous IL-2 on the Therapeutic Efficacy of IVS Effector Cells Generated from Lymph Node Cells of MCA 102 Plus C. parvum-Primed Mice

\begin{tabular}{ccc}
\hline & \multicolumn{2}{c}{$\begin{array}{c}\text { Mean no. metastases (SFM) } \\
\text { in vivo administration of }\end{array}$} \\
\cline { 2 - 3 } $\begin{array}{c}\text { No. IVS cells } \\
\text { transferred }^{b}\end{array}$ & HBSS & ${\mathrm{LL}-2^{c}}^{c}$ \\
\hline 0 & $182(22)$ & $95(16)$ \\
$1 \times 10^{6}$ & $110(30)$ & $107(19)$ \\
$3 \times 10^{6}$ & $52(8)$ & $21(16)^{d}$ \\
$7 \times 10^{6}$ & $4(3)^{d}$ & $3(1)^{d}$ \\
$15 \times 10^{6}$ & $1(1)^{d}$ & $1(1)^{d}$ \\
$30 \times 10^{6}$ & & \\
\hline
\end{tabular}

\footnotetext{
${ }^{a}$ B6 mice were inoculated sc with a mixture of $3 \times 10^{6} \mathrm{MCA} 102$ tumor cells and $25 \mu \mathrm{g}$ of $C$. parvum in $0.1 \mathrm{ml}$ of HBSS. Seven days later, draining inguinal $L N$ cells were cultured by the IVS method for 9 days with irradiated MCA 102 tumor cells in the presence of $10 \mathrm{U} / \mathrm{ml}$ of recombinant IL-2.

${ }^{b}$ B6 mice were injected iv with $3 \times 10^{5} \mathrm{MCA} 102$ tumor cells to initiate pulmonary metastases. Three days later, IVS cells were given iv in $1.0 \mathrm{ml}$ HBSS through the tail vein. Lungs were harvested and metastases counted 14 days after tumor injection.

${ }^{c} \mathrm{IL}-2(7500 \mathrm{U})$ was administered in $0.5 \mathrm{ml}$ of HBSS ip twice daily for 4 days starting on the day of cell transfer.

${ }^{d}$ Significantly different from groups without receiving IVS cells but treated with HBSS or IL-2 ( $P<0.05$, two-side $P$ values from a standard normal table; Wilcoxon rank-sum test).
}

Statistical analysis. The significance of differences in numbers of pulmonary metastases among groups was determined by the Wilcoxon rank-sum test (26). Twosided $P$ values were presented in all adoptive immunotherapy experiments.

\section{RESULTS}

Effect of exogenous IL-2 administration on adoptive immunotherapy mediated by MCA 102 tumor-primed, IVS lymphoid cells. We have previously shown that the adoptive transfer of IVS cells, derived from LN draining the inoculation site of MCA 102 tumor cells and C. parvum, in conjunction with low-dose IL-2 administration was therapeutically effective against established metastases (20). The role of IL-2 administration on the therapeutic efficacy of IVS cells was further evaluated. In the experiment summarized in Table 1, graded numbers of IVS LN cells given either alone or in combination with IL-2 administration were assessed for therapeutic efficacy in adoptive immunotherapy. Enumeration of metastatic nodules on Day 14 of tumor growth revealed that the antitumor efficacy was proportional to numbers of transferred IVS cells. Treatment with high doses of cells $\left(1.5\right.$ to $\left.3.0 \times 10^{7}\right)$ alone resulted in a significant reduction of tumors. However, the anti-tumor effects of IVS could be further enhanced by approximately threefold if exogenous IL-2 was concomitantly administered. Since the dose and schedule ( $7500 \mathrm{U}$, twice daily for 4 days) of IL-2 when used alone did not have significant antitumor efficacy, the effects of IL2 were likely on the transferred IVS cells by improving their function and/or survival in vivo.

Phenotype profile of in vivo primed $L N$ cells before and after IVS. It has been shown that the IVS procedure preferentially induced the proliferation of Lyt-2+ $\mathrm{T}$ lympho- 


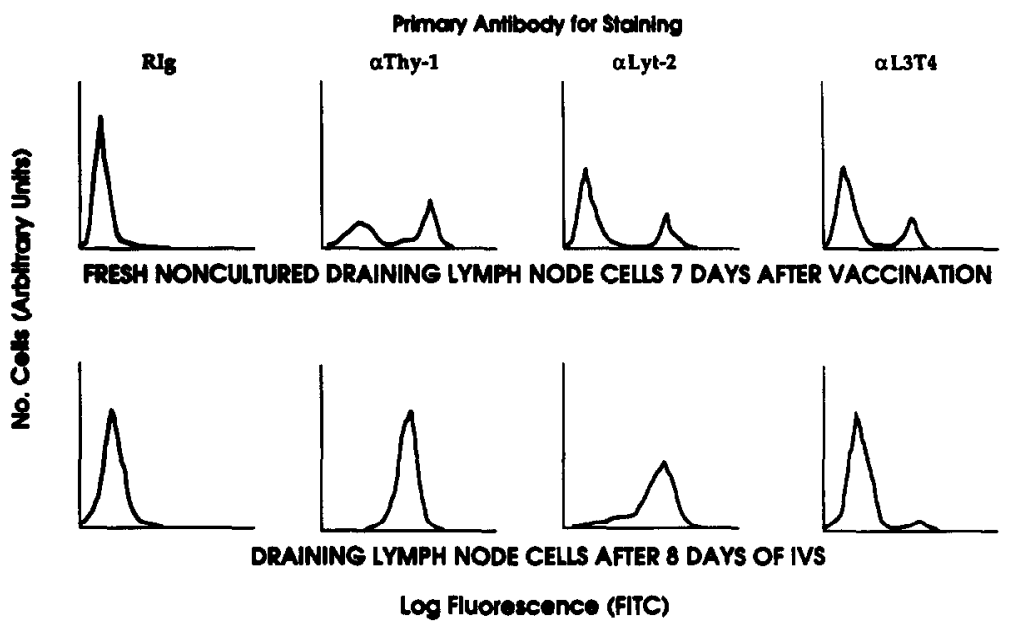

FIG. 1. Flow microfluorimetric analysis of lymphocytes freshly isolated from inguinal LN draining the inoculation site of MCA 102 tumor cells and C. parvum and the same lymphocytes after IVS with tumor cells in the presence of IL-2. Each analysis consisted of 10,000 cells.

cytes $(11,13)$. In the current study, analysis of freshly isolated, tumor-primed draining $\mathrm{LN}$ cells by FMF revealed $44 \%$ Thy- $1^{+}$cells with an equal distribution of $\mathrm{L} 3 \mathrm{~T}^{+}$ $(20 \%)$ and Lyt- $2^{+}(20 \%)$ cells (Fig. 1). However, after 8 days of culture in the presence of irradiated MCA 102 tumor cells and $10 \mathrm{U} / \mathrm{ml}$ of IL-2, virtually all cells expressed the Thy-1 $\mathrm{Ag}(97 \%)$. While the majority ( $82 \%$ ) of the IVS cells were Lyt-2+ lymphocytes, there was a small (7\%) but consistent fraction of cells expressing the L3T4 phenotype. Two-color FMF analysis (Fig. 2) indicated that the phenotypes of IVS

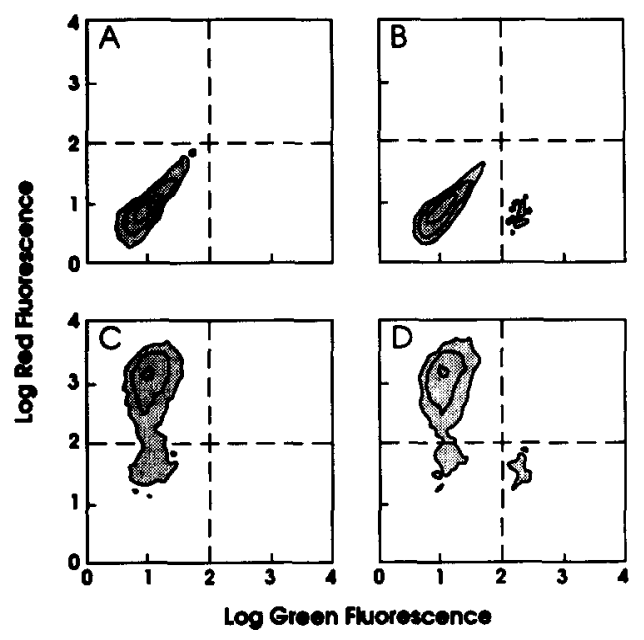

FIG. 2. Two-color FMF analysis of IVS cells derived from LN draining the inoculation site of MCA 102 tumor cells and $C$. parvum. Each frame represents 10,000 cells stained with (A) PE control; (B) FITC-antiL3T4; (C) Biotin-anti-Lyt-2 and PE; and (D) FITC-anti-L3T4, Biotin-anti-Lyt-2, and PE as described under Materials and Methods. 


\section{TABLE 2}

Effect of Specific Antibody Depletion of T Lymphocyte Subsets in Vivo on Adoptive Immunotherapy of Established MCA 102 Pulmonary Metastases with IVS Cells Generated from LN of MCA 102 TumorPrimed Mice

\begin{tabular}{ccccc}
\hline & & \multicolumn{3}{c}{ Mean no. metastases (SEM) $^{c}$} \\
\cline { 3 - 5 } IVS cells $^{a}$ & $\begin{array}{c}\text { mAb for in vivo } \\
\text { treatment }^{b}\end{array}$ & Expt 1 & Expt 2 & Expt 3 \\
\hline- & - & $244(6)$ & $236(13)$ & $230(13)$ \\
+ & RIg & $45(12)^{d}$ & $1(1)^{d}$ & $1(1)^{d}$ \\
+ & Anti-L3T4 & 250 & $161(44)$ & $40(9)^{d}$ \\
+ & Anti-Lyt-2 & 250 & 250 & $215(9)$ \\
\hline
\end{tabular}

${ }^{a}$ Adoptive immunotherapy protocols and preparation of IVS cells were identical to that described in Table 1, except $4 \times 10^{5} \mathrm{MCA} 102$ tumor cells were used to initiate pulmonary metastases. The numbers of IVS cells transferred were $2.0 \times 2.4 \times$ and $3 \times 10^{7} /$ mouse for Experiment 1,2 , and 3, respectively. Mice used in experiment 3 were whole-body irradiated $(500 \mathrm{R})$ before tumor inoculation.

${ }^{b}$ Two-tenths of a milliliter of ascites fluid diluted to $1.0 \mathrm{ml}$ with HBSS or $0.25 \mathrm{mg}$ of RIg was given iv within $1 \mathrm{hr}$ of cell transfer.

${ }^{c}$ Lungs were harvested and metastases counted 13 to 14 days after tumor injection.

${ }^{d}$ Significantly different from not treated groups $(P<0.05$, two-sided $P$ values from a standard normal table; Wilcoxon rank-sum test).

cells were either Lyt- $2^{+}, \mathrm{L} 3 \mathrm{~T} 4^{-}$or $\mathrm{Lyt}-2^{-}, \mathrm{L} 3 \mathrm{~T} 4^{+}$cells with no detectable doublepositive $\left(\mathrm{Lyt}-2^{+}, \mathrm{L} 3 \mathrm{~T} 4^{+}\right)$cell population.

Phenotype of antitumor effector cells analyzed by in vivo depletion with anti-L3T4 or anti-Lyt-2 $m A b$. To analyze the phenotype of effector $T$ cells responsible for mediating the regression of tumor metastases, we chose the established method of in vivo depletion by specific mAb injections (13). B6 mice with 3-day established pulmonary MCA 102 metastases were treated by IVS cells and followed immediately by mAb injection to deplete $\mathrm{L} 3 \mathrm{~T}_{4}{ }^{+}$or Lyt- $2^{+} \mathrm{T}$ cells. Under certain circumstances, the administration of IL-2 has been reported to substitute for the helper function of L3T $4^{+}$cells $(12,27)$. Since IVS cells alone could mediate antitumor effects (Table 1), phenotype analysis was carried out without the administration of exogenous IL-2. In three independent experiments shown in Table 2 , systemic transfer of IVS cells markedly reduced the number of metastases in both normal and sublethally irradiated hosts. However, the therapeutic effect of transferred IVS cells was completely abrogated following in vivo $\mathrm{mAb}$ depletion of Lyt $-2^{+}$cells. In addition, depletion of $\mathrm{L} 3 \mathrm{~T} 4^{+}$cells resulted in substantial loss of therapeutic effects of the transferred cells. To ascertain the long-term effects of cellular depletion in vivo, we analyzed the phenotypes of spleen cells from mAb-treated animals. As shown in Table 3, greater than $90 \%$ specific depletion of $\mathrm{L}_{3} \mathrm{~T}^{+}$and $\mathrm{Lyt}-2^{+}$cells in mice treated with anti-L3T4 and antiI yt-2 mAb, respectively, was observed. Since L3T $4^{+}$and Lyt- $2^{+}$cells represent two separate populations of lymphocytes (Fig. 2), tumor regression was apparently mediated through the collaboration of these two subsets of IVS cells.

Evidence for the helper function of L3T $4^{+}$IVS cells. Murine T lymphocytes expressing the L3T4 phenotype have been identified to be closely associated with $\mathrm{T}$ cells of helper/inducer function $(28,29)$. We therefore examined whether the antitumor reactivity of this subset of IVS cells was mediated through their ability to secrete IL- 
TABLE 3

FMF Analysis of Spleen Cells 11 Days after in Vivo Administration of Antibodies

\begin{tabular}{cccc}
\hline & \multicolumn{3}{c}{ \% Positive cells $^{b}$} \\
\cline { 2 - 4 } mAb for in vivo treatment & \\
\cline { 2 - 4 } & Thy 1.2 & L3T4 & Lyt-2 \\
\hline RIg & 21.7 & 17.3 & 7.3 \\
Anti-L3T4 & 28.9 & 21.6 & 8.1 \\
Anti-Lyt-2 & 5.2 & 0.9 & 7.9 \\
\hline
\end{tabular}

\footnotetext{
${ }^{a}$ Lymphocytes were prepared from spleens of mice used in Table 2, Experiment 2.

${ }^{b}$ A total of 10,000 cells were analyzed in each staining. Percentage of positive cells was calculated based on protiles of negative staining with medium.
}

2. In the experiment summarized in Table 4, IL-2 or HBSS was given to mice whose T cell subsets were depleted following adoptive immunotherapy with IVS cells. Administration of IL-2 restored the antitumor efficacy of $\mathrm{L} 3 \mathrm{~T}^{+}$cell-depleted but not Lyt-2 ${ }^{+}$cell-depleted animals. These results indicate that the function of $\mathrm{L}_{3} \mathrm{~T}^{+}$cells could be substituted by IL-2 administration. Since the function of Lyt-2 $2^{+}$IVS cells could not be reconstituted by exogenous IL-2, these cells may contribute directly as antitumor effector cells. Consistent with the result of Table 1 experiments, the administration of IL-2 improved the therapeutic efficacy of IVS cells in mice that were not depleted of $\mathrm{T}$ cells.

Immunologic specificity of in vivo priming for eliciting preeffector cells. The generation of effective therapeutic cells against the MCA 102 tumor required initial priming of the syngeneic mice with tumor cells admixed with C. parvum. Since normal LN

TABLE 4

Effect of Exogenous IL-2 Administration on Antitumor Reactivity of IVS Cells after Depletion in Vivo of $\mathrm{L} 3 \mathrm{~T} 4^{+}$or Lyt-2 ${ }^{+}$Cells by mAb

\begin{tabular}{cccc}
\hline & mAb for in vivo $_{\text {Transfer of }}$ & \multicolumn{2}{c}{$\begin{array}{c}\text { Mean no. metastases (SEM) } \\
\text { in vivo administration of }\end{array}$} \\
\cline { 3 - 4 } IVS cells $^{a}$ & \multicolumn{1}{c}{ HBSS } & IL-2 $^{c}$ \\
\hline- & RIg & 250 & 250 \\
+ & Anti-L3T4 & $49(21)^{e}$ & $1(1)^{e}$ \\
+ & Anti-Lyt-2 & $239(10)$ & $3(1)^{e}$ \\
+ & & 250 & 250 \\
\hline
\end{tabular}

${ }^{a}$ Adoptive immunotherapy protocols and preparation of IVS cells were identical to those described in Table 1 except each mouse received iv transfer of $3.0 \times 10^{7}$ IVS cells.

${ }^{b}$ Schedule of injections and dilutions of $\mathrm{mAb}$ used were the same as described in Table 2.

${ }^{c}$ IL-2 $(7500 \mathrm{U})$ was administered in $0.5 \mathrm{ml}$ of HBSS ip twice daily for 4 days starting on the days of IVS cell transfer.

${ }^{d}$ Lungs were harvested and metastases counted 14 days after tumor injection.

${ }^{e}$ Significantly different when compared with groups without receiving IVS cells but treated with HBSS or IL-2 $(P<0.05$, two-sided Wilcoxon rank-sum test). 
TABLE 5

Immunologic Spccificity of in Vivo Priming for Eliciting Preeffector Cells to the MCA 102 Tumor

\begin{tabular}{|c|c|c|c|c|}
\hline \multirow{3}{*}{$\begin{array}{l}\text { Tumor used for } \\
\text { in vivo priming }\end{array}$} & \multicolumn{4}{|c|}{ Adoptive immunotherapy ${ }^{b}$} \\
\hline & \multirow{2}{*}{$\begin{array}{l}\text { In vivo } \\
\text { IL-2 }\end{array}$} & \multicolumn{3}{|c|}{ Mean no. metastases $(\mathrm{SEM})^{d}$} \\
\hline & & Expt 1 & Expt 2 & Expt 3 \\
\hline & - & $163(36)$ & $114(19)$ & 250 \\
\hline & + & $90(18)$ & $126(26)$ & 250 \\
\hline MCA 101 & + & $46(14)$ & $111(49)$ & $119(26)$ \\
\hline MCA 102 & + & $14(6)^{e}$ & $18(8)^{e}$ & $3(2)^{e}$ \\
\hline MCA 105 & + & $85(38)$ & $71(25)$ & $137(6)$ \\
\hline MCA 106 & + & $7(3)^{c}$ & $34(11)^{e}$ & $38(7)^{e}$ \\
\hline
\end{tabular}

${ }^{a}$ Cells $\left(3 \times 10^{6}\right)$ from each tumor were admixed with $25 \mu \mathrm{g} C$. parvum and were given sc to each mouse in $0.1 \mathrm{ml}$. Seven days later, draining inguinal LN cells were cultured according to the IVS method for 9 days.

${ }^{b}$ Adoptive immunotherapy of established MCA 102 metastases was carried out identically to that of experiments described in Table 2 except $1.5 \times 10^{7}$ (Experiments 1 and 2) and $3 \times 10^{7}$ (Experiment 3) cells were transferred iv to each mouse.

${ }^{c} \mathrm{IL}-2$ (7500 U for Experiments 1 and 2, $15,000 \mathrm{U}$ for Experiment 3) was administered in $0.5 \mathrm{ml}$ of $\mathrm{HBSS}$ ip twice daily for 4 days starting on the day of IVS cell transfer.

${ }^{d}$ Lungs were harvested and metastases counted 12 to 14 days after tumor injection.

e Significantly different from groups without treatment or treated with $\mathrm{IL}-2$ only $(P<0.05$, two-side $P$ values, Wilcoxon rank-sum test).

or LN responding to injections of $C$. parvum alone did not have antitumor reactivity after IVS (20), it became apparent that the sensitization for preeffector LN cells required stimulation by tumor cells. We therefore examined immunologic specificity of this requirement by using several other syngeneic sarcomas. B6 mice were inoculated sc with $3 \times 10^{6} \mathrm{MCA} 101$, MCA 102, MCA 105, or MCA 106 tumor cells admixed with $25 \mu \mathrm{g} C$. parvum. Seven days later, draining $\mathrm{LN}$ were harvested for IVS with irradiated MCA 102 tumor cells and IL-2. Cells harvested after 8 days of culture were tested for antitumor efficacy in adoptive immunotherapy experiments. As shown in Table 5, 3-day established pulmonary MCA 102 metastases were treated with these IVS cells. On Days 12 to 14 after tumor inoculation, enumeration of the numbers of metastatic nodules revealed that significant reduction in tumors was accomplished by infusion of IVS cells derived from either MCA 102- or MCA 106primed LN. LN cells from MCA 101- and MCA 105-primed animals did not give rise to therapeutic cells. These results indicate that eliciting preeffector cells, although restricted, did not seem to be MCA 102 tumor-specific.

Requirement and specificity of tumor stimulation in IVS for generation of therapeutic lymphocytes. Primed LN cells contained preeffector cells which did not have in vivo antitumor efficacy (20). Generation of therapeutically effective cells required additional secondary IVS with tumor cells and IL-2. In the absence of IL-2, no cellular proliferation was observed. However, cellular proliferation could proceed in the absence of tumor stimulation but the resulting cells did not demonstrate antitumor efficacy. We therefore analyzed the specificity of tumor stimulation during IVS. In addition to normal spleen cells, four syngeneic sarcomas including MCA 101, MCA 
TABLE 6

Specificity of Tumor Stimulation during IVS for Generating Therapeutic Lymphocytes from MCA 102-Primed LN Cells

\begin{tabular}{lccccc}
\hline & \multicolumn{5}{c}{ Adoptive immunotherapy $^{b}$} \\
\cline { 2 - 6 } $\begin{array}{c}\text { Tumor stimulator } \\
\text { cells for IVS } \\
(\text { no./well) }\end{array}$ & $\begin{array}{c}\text { In vivo } \\
\text { IL-2 }^{c}\end{array}$ & Expt. 1 & Expt. 2 & Expt. 3 & Expt. 4 \\
\cline { 3 - 7 } & - & $246(3)$ & $163(22)$ & $193(22)$ & $228(13)$ \\
& + & $230(18)$ & $101(11)$ & $212(11)$ & $212(15)$ \\
Normal spleen $\left(1 \times 10^{6}\right)$ & + & & $66(7)$ & & $119(18)$ \\
MCA 101 $\left(2 \times 10^{5}\right)$ & + & & & & $163(33)$ \\
MCA 102 $\left(2 \times 10^{5}\right)$ & + & $5(4)^{e}$ & $8(4)^{e}$ & $0^{e}$ & $24(6)^{e}$ \\
MCA 105 $\left(4 \times 10^{5}\right)$ & + & $1(1)^{e}$ & & $10(4)^{e}$ & \\
MCA 106 $\left(1 \times 10^{5}\right)$ & + & & $16(3)^{e}$ & $4(1)^{e}$ & \\
\hline
\end{tabular}

${ }^{a}$ All tumor stimulator cells were irradiated at a dosage of $4000 \mathrm{R}$ before use for IVS. Normal spleen cells were irradiated at $1000 \mathrm{R}$.

${ }^{b}$ Adoptive immunotherapy protocols were identical to those described in Table 2 . The numbers of IVS cells transferred were $1.4 \times, 1 \times, 1 \times$, and $1.2 \times 10^{7}$ /mouse for Expt. 1, 2, 3, and 4, respectively.

${ }^{c}$ IL-2 $(7500 \mathrm{U})$ was administered in $0.5 \mathrm{ml}$ of HBSS ip twice daily for 4 days starting on the day of IVS cell transfer.

${ }^{d}$ Lungs were harvested and metastases counted 12 to 14 days after tumor injection.

e Significantly different from groups without treatment or treated with IL-2 only $(P<0.05$, two-side $P$ values, Wilcoxon rank-sum test).

102, MCA 105, and MCA 106 tumors were tested. The number of tumor cells added to each well was determined in preliminary experiments to form approximately $50 \%$ confluence at $24 \mathrm{hr}$ after culture. As can be seen in Table 6, various numbers of irradiated tumor cells were used for the stimulation of MCA 102-primed LN cells. Evaluation of anti-tumor efficacy by adoptive immunotherapy experiments revealed that IVS cells stimulated by not only MCA 102 but also by MCA 105 or MCA 106 tumor cells exhibited potent therapeutic effects. Stimulation with MCA 101 or normal spleen cells did not lead to the generation of antitumor effector cells. Thus, the in vitro antigenic stimulation can be fulfilled by several other syngeneic sarcoma cells. It is also noteworthy that the MCA 105 tumor was not capable of eliciting preeffector cells when used for priming syngeneic mice (Table 5).

Specificity of adoptive immunotherapy with MCA 102 tumor-primed, IVS LN cells. Adoptive immunotherapy mediated by sensitized $\mathrm{T}$ lymphocytes has generally been shown to be immunologically specific to individual, chemically induced tumors $(5$, $8,9)$. Since the MCA 102 tumor does not possess demonstrable TSTA $(16,20)$ and considerable cross-reactivity was seen during sensitization in vivo and in vitro (Tables 5 and 6), it is suspected that the target Ag recognized by the MCA 102-sensitized T cells might not be MCA 102 tumor-specific. The specificity of tumor regression mediated by the IVS cells was thus analyzed. Mice bearing pulmonary metastases derived from the MCA 101, MCA 102, MCA 105, and MCA 106 tumors were treated with MCA 102 tumor-primed, IVS LN cells. In these experiments (Table 7), mice receiving sensitized cells were also treated with IL-2 for 4 days to enhance the therapeutic efficacy. Evaluation of the numbers of metastatic nodules revealed that the IVS cells 
TABLE 7

Specificity of Adoptive Immunotherapy Mediated by IVS Cells from MCA 102-Primed LN Cells

\begin{tabular}{|c|c|c|c|c|c|c|}
\hline & \multirow[b]{3}{*}{ IVS cells ${ }^{a}$} & \multirow{3}{*}{$\begin{array}{c}\text { In vivo } \\
\text { IL-2 }\end{array}$} & \multicolumn{4}{|c|}{ Mean no. metastases (SEM) } \\
\hline & & & \multicolumn{4}{|c|}{ Tumor $^{b}$} \\
\hline & & & MCA 101 & MCA 102 & MCA 105 & MCA 106 \\
\hline \multirow[t]{3}{*}{ Experiment 1} & - & - & 250 & $187(18)$ & 250 & 250 \\
\hline & - & + & 250 & $218(19)$ & 250 & $210(24)$ \\
\hline & + & + & $249(1)$ & $21(3)^{c}$ & $171(19)^{c}$ & $58(13)^{c}$ \\
\hline \multirow[t]{3}{*}{ Experiment 2} & - & - & $209(16)$ & $108(17)$ & $232(14)$ & $46(11)$ \\
\hline & - & + & $208(18)$ & $63(12)$ & 250 & $50(26)$ \\
\hline & + & + & $150(22)$ & $1(1)^{c}$ & $9(3)^{c}$ & $2(1)^{c}$ \\
\hline
\end{tabular}

${ }^{a}$ Adoptive immunotherapy protocols and doses and schedule of IL-2 administration were the same as that described in Table 1. The number of IVS cells transferred/mouse was $1.2 \times 10^{7}$.

${ }^{b}$ The numbers of tumor cells given iv to initiate pulmonary metastases were $6 \times 10^{5}$ for MCA 101, 2 to $4 \times 10^{5}$ for MCA $102,2 \times 10^{5}$ for MCA 105 and 4 to $8 \times 10^{5}$ for MCA 106. All mice receiving MCA 105 tumor cells were treated with $100 \mathrm{mg} / \mathrm{kg}$ of cyclophosphamide iv $6 \mathrm{hr}$ before tumor inoculation. Lungs were harvested and metastases counted 14 to 20 days after tumor injection.

${ }^{c}$ Significantly different from groups without treatment or treated with IL-2 only $(P<0.05$, two-side $P$ valued, Wilcoxon rank-sum test).

displayed therapeutic activities not only against the MCA 102 tumor but also against the MCA 105 and MCA 106 tumors. However, this cross-reactivity was not seen when IVS cells were tested in animals with the MCA 101 tumor. It thus appears that regression of the MCA 102 tumor mediated by the IVS cells was through the recognition of a set of cross-reacting Ag presented not only on MCA 102 tumor cells but also on other syngeneic tumors.

\section{DISCUSSION}

Successful adoptive immunotherapy of tumors is critically dependent on the ability to identify and isolate potent immune effector lymphocytes. The transplantation rejection techniques used to demonstrate tumor-specific $\mathrm{Ag}$ on animal tumors have also provided a convenient means for sensitization of a large quantity of immune cells for experimental studies. Therefore, the use of animal tumors that are capable of eliciting transplantation immunity has been an essential component for studies of adoptive immunotherapy. If the therapeutic potential and clinical problems associated with this approach can be defined in animal models, it becomes necessary to demonstrate the feasibility of adoptive immunotherapy against tumors that lack conventional TSTA because the presence of comparable immunologically active Ag on spontaneous human tumors has not been established with certainty. Toward this goal, we have selected and defined a murine tumor, MCA 102, with which systemic immunity could not be elicited in its syngeneic hosts. In a previous publication (20), we have reported that therapeutically effective lymphocytes against the MCA 102 sarcoma could be induced by in vivo and in vitro immunological manipulations. Some fundamental principles and methodology to achieve this have been described 
previously. In the current study, we have analyzed the T cell phenotype of IVS cells that mediated in vivo elimination of pulmonary MCA 102 metastases. Because of lack of demonstrable TSTA on the MCA 102 tumor, biological characteristics of the target $\mathrm{Ag}$ recognized by these IVS cells was examined by analyzing immunologic specificity using several additional syngeneic tumors.

For $\mathrm{T}$ cell phenotype analyses, we chose to use the procedure of in vivo depletion with L3T4 or Lyt-2 mAb because of previous experience with this technique (11-13, 16). In previous studies using the immunogenic MCA 105 tumor, we found that the IVS procedure preferentially induced Lyt- $2^{+}$cell proliferation and this $\mathrm{T}$ cell population alone constituted the entire in vivo antitumor reactivity $(11,13)$. In contrast, the regression of established MCA 102 metastases was mediated through the collaboration of $\mathrm{L} 3 \mathrm{~T}^{+}$and Lyt-2 $2^{+}$cells. This conclusion is supported by the fact that elimination of either $\mathrm{L} 3 \mathrm{~T}^{+}{ }^{+}$or Lyt-2 $2^{+}$cells abrogated in vivo antitumor effects (Table 2) and ${\mathrm{L} 3 \mathrm{~T}^{+}}^{+}$and Lyt-2 ${ }^{+}$cells represented two distinct cell populations (Fig. 2). Evidence that both cell populations are from transferred donor cells comes from the experiment where recipient mice for adoptive immunotherapy were sublethally irradiated to suppress host $T$ cell function (Table 2).

Identification of the $T$ cell phenotype associated with regression of established tumors was originally thought to be able to elucidate a unique cellular mechanism responsible for in vivo tumor destruction. However, documented studies have indicated that virtually all $\mathrm{T}$ cell subsets either alone or in combination could potentially effect tumor regression in vivo $(11,30-34)$. The differences in effector $T$ cells appear to reflect more on the difference between tumor models employed rather than representing inconsistent findings. Perhaps it should be viewed that different tumors may elicit different types of immune response. The characteristics of immune response elicited may depend on the structural nature of tumor-associated $\mathrm{Ag}$ and more importantly, the intrinsic immunogenicity of the tumor to its syngeneic host.

Despite the differences between experimental tumor models and effector $\mathrm{T}$ lymphocytes, the efficacy of adoptive immunotherapy mediated by cultured $T$ cells can always be enhanced by concomitant administration of IL-2 (10, 13, 34-36). Similarly, the therapeutic efficacy of MCA 102 IVS cells was improved with exogenous IL-2 injections (Table 1). In the past, the ability of exogenous IL-2 to augment the function of Lyt- $2^{+}$effector lymphocytes was interpreted as a result of improved survival and proliferation of the transferred cells since cultured cells were somewhat "addicted" to IL-2 $(34,35)$. While this interpretation is supported by our experimental results, we have identified an additional function exerted by exogeneous IL-2. It is quite clear from data presented in Table 4 that the administration of IL-2 could negate the need for $\mathrm{L} 3 \mathrm{T4}^{+}$but not for Lyt-2 ${ }^{+}$IVS cells in adoptive immunotherapy. Whether the effect of IL-2 is expressed through providing a helper function for and/ or improving the proliferation of Lyt- $2^{+}$cells, the issue does not deserve further discussion here because the function of L3T $4^{+}$IVS cells in adoptive immunotherapy of the MCA 102 tumor seems to be associated with their ability to provide IL-2. It is clear, however, that cells of the Lyt-2 phenotype are the predominant effector cells.

Contrary to the antitumor reactivity expressed by NK or lymphokine-activated killer (LAK) cells, reactions mediated by sensitized $T$ lymphocytes are, in general, immunologically specific with regard to tumors. However, the procedure for generating sensitized $T$ cells in this study was quite different from conventional immunization methods. In addition, there was no evidence of the presence of TSTA on the 
MCA 102 tumor (20). We therefore suspected that the Ag involved for sensitization of $T$ cells in this case might not be representative of TSTA and under normal circumstances, was not sufficiently immunogenic. To define the biological nature of $\mathrm{Ag}$ on the MCA 102 tumor that are responsible for $T$ cell sensitization as well as for $T$ cellmediated tumor regression, we selected several well defined syngeneic tumors of similar histologic origin but different in their immunogenicity as controls for specificity analyses. The MCA 105 and MCA 106 sarcomas have been defined as weakly immunogenic because immunization of syngeneic mice with tumor cells admixed with $C$. parvum resulted in acquisition of systemic immunity (9). The MCA 101 sarcoma is considered to be nonimmunogenic because all attempts to immunize syngeneic animals have failed (16).

The procedure for generating therapeutic T lymphocytes to the MCA 102 tumor involved in vivo priming followed by IVS of primed LN cells. The IVS was carried out by culturing LN cells with tumor stimulator cells in the presence of IL-2. The use of IL-2 in IVS was essential for lymphocyte proliferation. The presence of tumor cells was thought to provide antigenic stimulation for the primed lymphocytes $(10,13)$. Indeed, IVS cells generated in response to normal spleen cells proved to be ineffective for tumor therapy. However, using other syngeneic tumors, we have found that this in vitro secondary antigenic stimulation was not strictly specific immunologically. While MCA 101 tumor cells failed to serve as effective $\mathrm{Ag}$, the immunogenic MCA 105 and MCA 106 tumors were as efficient as the MCA 102 tumor for in vitro stimulation (Table 6). In previous studies, we found that both the MCA 105 and MCA 106 tumors possessed TSTA (9) and the generation of therapeutically effective lymphocytes against these tumors by IVS from either immune spleen cells or lymphoid cells of tumor-bearing mice required specific stimulation by corresponding tumor cells $(10,14)$. Therefore, the cross-reactivity observed in this study must reflect shared antigenic determinants between the MCA 102, MCA 105, and MCA 106 tumors that were distinct from TSTA presented on MCA 105 or MCA 106 tumor cells.

The conditions and requirements for eliciting preeffector cells in vivo have also been extensively analyzed (20). It was concluded that both tumor cells and the bacterial adjuvant, $C$. parvum, were required for sensitization of preeffector cells. In this study, we have analyzed the immunologic specificity of the in vivo priming. The results of such experiments (Table 5) revealed that similar to the conditions of antigenic stimulation during IVS, the in vivo reaction was also not strictly tumor specific. While both the MCA 102 and MCA 106 tumors were effective, LN cells from either MCA 101- or MCA 105 tumor-primed animals failed to give rise to therapeutically effective cells after IVS. Considering the antigenic cross-reactivity between the MCA 102, MCA 105, and MCA 106 tumors during IVS, it is conceivable that the sensitization of lymphocytes during in vivo priming and IVS has different requirements with respect to antigenic recognition. The exact molecules involved for the two immunologic reactions are yet to be defined. It may be hypothesized that the in vivo priming involves the sensitization of $\mathrm{T}$ cells to a set of common tumor-associated $\mathrm{Ag}$ which are present on MCA 102, MCA 105, and MCA 106 tumor cells. However, the mere presence of the common Ag is not sufficient for in vivo sensitization since MCA 105 tumor cells failed to do so. It is likely that additional structures presented on MCA 102 and MCA 106 but not MCA 105 tumor cells are also required to facilitate the preeffector cell response. Once sensitized, the presence of common $\mathrm{Ag}$ appear to be sufficient for stimulating the secondary immune response during IVS. If this is the 
case, the failure of the MCA 101 tumor for both in vivo priming and in vitro stimulation could be interpreted as the lack of tumor-associated antigenic determinants.

With regard to immunologic specificity, it was interesting to note that adoptive immunotherapy with IVS cells displayed specificity similar to that of antigenic stimulation during IVS. From the data in Table 7, the transfer of IVS cells apparently mediated the regression of not only MCA 102 but also MCA 105 and MCA 106 tumor metastases with little or no antitumor reactivity toward the MCA 101 tumor. Consistent with our hypothesis, tumor regression appeared to be mediated through the recognition of the common Ag shared by those tumors. Although both the MCA 105 and MCA 106 tumors contained TSTA (9), it is unlikely that the regression of these tumors mediated by MCA 102 tumor-primed and secondarily IVS cells involved individual TSTA because IVS cells specifically sensitized to the two tumors failed to mediate the regression of the MCA 102 tumor (14). Taken together, studies on the specificity of the immune response at both afferent and efferent limbs revealed that TSTA were not necessarily the only Ag that could serve as the target molecules for $\mathrm{T}$ cell-mediated antitumor immunity. In fact, our results in this study provided evidence of the existence of common tumor-associated $\mathrm{Ag}$ on both immunogenic and nonimmunogenic syngeneic tumors. $T$ lymphocytes with reactivity against these Ag could mediate effectively the regression of tumors in vivo.

The experimental results summarized in this paper define the nature of effector $T$ lymphocytes responsible for regression of the MCA 102 sarcoma. Although the MCA 102 tumor does not appear to possess classical TSTA, the presence of other tumorassociated Ag on the MCA 102 sarcoma can be exploited for its immunologic rejection. The chemical and structural properties of these $\mathrm{Ag}$ are yet to be defined. It appears that induction of $\mathrm{T}$ cell immunity to these $\mathrm{Ag}$ requires both in vivo and in vitro manipulations. However, $\mathrm{T}$ cells with reactivity to these $\mathrm{Ag}$ are fully capable of mediating antitumor effects. Since the target Ag were detected on several other syngeneic tumors including the MCA 105 and MCA 106 tumors, it would be interesting to explore their possible existence on normal tissues as well as allogeneic tumors. Also interesting is the finding that these $\mathrm{Ag}$ alone were not sufficiently "immunogenic" to provoke a preeffector cell response. Isolation, chemical modification, and xenogeneization of the $\mathrm{Ag}$ may prove to be promising approaches for immunotherapy of tumors which do not possess apparent TSTA.

\section{ACKNOWLEDGMENTS}

The authors thank the Cetus Corporation for supplying recombinant IL-2, Ms. Kathryn A. Aker for her excellent technical assistance, and Ms. Debbie Birdsall for the preparation of this manuscript.

\section{REFERENCES}

1. Mitchison, N. A., J. Exp. Med. 102, 157, 1955.

2. Delorme, E. J., and Alexander, P., Lancet 2, 117, 1964.

3. Borberg, H., Oettgen, H. F., Choudry, K., and Beattie, E. J., Jr., Int. J. Cancer 10, 539, 1972.

4. Cheever, M. A., Kempf, R. A., and Fefer, A., J. Immunol. 119, 714, 1977.

5. Rosenberg, S. A., and Terry, W., Adv. Cancer Res. 25, 323, 1977.

6. Smith, H. G., Harmel, R. P., Hanna, M. G., Jr., Zwelling, B. S., Zbar, B., and Rapp, H. J., J. Natl. Cancer Inst. 58, 1315, 1977.

7. Fernandez-Cruz, E., Halliburton, B., and Feldman, J. D., J. Immunol. 123, 1772, 1979.

8. Fefer, A., Cheever, M. A., and Greenberg, P. D., In "Immunological Approaches to Cancer Therapeutics", (E. Mihich, Ed.), p. 333. Wiley, New York, 1982. 
9. Shu, S., and Rosenberg, S. A., Cancer Res. 45, 1657, 1985.

10. Shu, S., Chou, T., and Rosenberg, S. A., J. Immunol. 136, 3891, 1986.

11. Shu, S., Chou, T., and Rosenberg, S. A., Cancer Res. 47, 1354, 1986.

12. Ward, B. A., Shu, S., Chou, T., Perry-Lalley, D., and Chang, A. E., J. Immunol. 141, 1047, 1988.

13. Shu, S., Chou, T., and Rosenberg, S. A., J. Immunol. 139, $295,1987$.

14. Chou, T., Chang, A. E., and Shu, S., J. Immunol. 149, 2453, 1988.

15. Chou, T., Bertera, S., Chang, A. E., and Shu, S., J. Immunol. 141, 1775, 1988.

16. Mule, J., Yang, J. C., Lafreniere, R., Shu, S., and Rosenberg, S. A., J. Immunol. 139, 285, 1987.

17. Hewitt, H. B., Blake, E. R., and Walder, A. S., Brit J. Cancer 33, 241, 1976.

18. Hewitt, H. B., Adv. Cancer Res. 27, 149, 1978.

19. Weiss, D., Cancer Immunol. Immunother. 2, 11, 1977.

20. Shu, S., Chou, T., and Sakai, K., J. Immunol 143, 740, 1989.

21. Asher, A. L., Mule, J. J., Reichert, C. M., Shiloni, E., and Rosenberg, S. A., J. Immunol. 138, 963 , 1987.

22. McIntosh, J. K., Mule, J. J., Merino, M. J., and Rosenberg, S. A., Cancer Res. 48, 401 1, 1988.

23. Rosenberg, S. A., Spiess, P. J., and Lafreniere, R., Science 233, $1318,1986$.

24. Spiess, P. J., Yang, J. C., and Rosenberg, S. A., J. Natl. Cancer Inst. 79, 1067, 1987.

25. Wexler, H., J. Natl. Cancer Inst. 36, 641, 1966.

26. Gehan, E., Biometrika 52, 203, 1965.

27. Chou, T., and Shu, S., J. Immunol. 139, 2103, 1987.

28. Dialynas, D. P., Quan, Z. S., Wall, K. A., Pierres, A., Quintans, J., Loken, M. R., Pierres, M., and Fitch, F. W., J. Immunol. 131, 2445, 1983.

29. Dialynas, D. P., Wilde, D. B., Marrack, P., Pierres, A., Wall, K. A., Havran, W., Otten, G., Loken, M. R., Pierres, M., Kappler, J., and Fitch, F. W., Immunol Rev. 74, 29, 1983.

30. Fernandez-Cruz, E., Woda, B. A., and Feldman, J. D., J. Exp. Med. 152, 823, 1980.

31. Greenberg, P. D., Cheever, M. A., and Fefer, A., J. Exp. Med. 154, 952, 1981.

32. Greenberg, P. D., Kern, D. E., and Cheever, M. A., J. Exp. Med. 161, 1122, 1985.

33. Rosenstein, M., Fherlein, T. I., and Rosenherg, S. A., J. Immunol. 132, 2117, 1984.

34. Greenberg, P. D., J. Immunol. 136, 1917, 1986.

35. Cheever, M. A., Greenberg, P. D., and Fefer, A., J. Immunol. 126, $1318,1981$.

36. Cheever, M. A., Greenberg, P. D., Irle, C., Thompson, J. A., Ural, D. L., Mochizuki, D. Y., Henney, C. S., and Gillis, S., J. Immunol. 132, 2259, 1984. 